\title{
Research on the Reform of Financial Reimbursement Process Brought by Electronic Invoice
}

\author{
Songyue Liu \\ School of Management \\ Wuhan University of Technology \\ Wuhan, China 430070
}

\author{
Lei Xia \\ School of Management \\ Wuhan University of Science and Technology \\ Wuhan, China 430081
}

\begin{abstract}
Since the first electronic invoice was issued by Jingdong Mall in 2013, the scale of the issuance of electronic invoices in China has been expanding. Compared with paper invoices, the application of electronic invoices for financial reimbursement can effectively save costs and improve efficiency. At the same time, it can solve the problem of untimely approval of enterprises due to mobile office. This paper analyzes the financial sharing reimbursement process and the electronic invoice reimbursement process, summarizes the problems arising from the current electronic invoice application in corporate financial reimbursement, draws on the experience of E-invoice implementation in Brazil, Taiwan, EU and other regions, and proposes the concept of fully implementing electronic invoice in China.
\end{abstract}

Keywords-electronic invoice; financial sharing; financial reimbursement

\section{INTRODUCTION}

The electronic invoice liberates the financial personnel from the application, collection, issuance, circulation, verification, binding, archiving and other aspects of paper invoices. This will save paper costs, the cost of express delivery, travel cost and other circulation costs, and ensure the real-time reimbursement. Applying an electronic invoice can save the cost of non-mailing invoices by 1-1.7 yuan, and save the cost of mailing invoices by 7-14 yuan. [1] Electronic invoices can also help reduce manual input errors, reduce the risk of losing tickets, and standardize national tax collection of e-commerce platforms. In addition to the transparency of the electronic invoice workflow, the traceability of electronic invoices should be improved. [2] The "Accounting Law" stipulates that original bills, financial vouchers, and financial books should be printed, bound, and archived. The accounting files must not be destroyed in 15 years. A large number of paper vouchers increase the cost of the enterprise, and file access is also difficult, resulting in paper waste. In 2015, the state proposed an electronic file management method, and the electronic file obtained legal status. The original documents of the enterprise are mostly based on paper invoices, and the electronicization of the invoices is helpful to promote the implementation of electronic files as soon as possible.

In 2012, the online invoice was successfully piloted in Beijing. In 2013, Jingdong Mall issued the first upgraded version of the value-added tax electronic invoice. After replacing business tax with value-added tax in 2016, the electronic invoice was widely used in companies that issued printed invoice, such as e-commerce and express delivery, supermarket, transportation, telecommunications, financial and insurance industries. In 2017, the Ministry of Transport issued "Announcement of the State Administration of Taxation on the issuance of electronic ordinary value-added tax invoices for road tolls and other matters". It pointed out that people can print the value-added tax electronic invoices of tolls. China's safe electronic invoicing system, regional electronic invoice information management and service platform, and electronic invoice information exchange and sharing platform led by the National Engineering Laboratory of E-Commerce Transaction Technology have accumulated more than 378 million electronic invoices during the application period. It saves the enterprise cost exceeds 300 million yuan, and saving more than 60 tons of paper. [1]

Therefore, the advantages of applying electronic invoices are obvious. However, for companies accustomed to the original way of reimbursement, there are many challenges and risks. For enterprises, financial reimbursement is an important part of enterprise cost confirmation. Financial personnel need to spend a lot of time in reimbursement. Therefore, this paper analyzes the development status of enterprise reimbursement mode, proposes a new reimbursement model brought by electronic invoice, and combines financial sharing to analyze the financial reimbursement reform of enterprises and the application of electronic invoice reimbursement.

\section{THE FINANCIAL SHARING REIMBURSEMENT MODEL}

\section{A. Financial Sharing Reimbursement Process}

Due to the drawbacks of the traditional online reimbursement model, the financial staff of the company is constantly looking for solutions. The organizational structure of the financial department has changed from the decentralized management to centralized management. The organizational structure has been re-engineered. A new generation of network reimbursement model based on financial sharing has emerged. This centralized network reimbursement model based on financial sharing has the characteristics of flexibility, real-time information sharing, 
access and delivery. The standardized web design, electronic financial accounting, digital fund management and collaboration process are achieved. The reimbursement process realizes the seamless docking among the enterprise ERP system, the OA system, the monetary fund system and the financial accounting system.

The financial sharing reimbursement process is shown in "Fig. 1". The business personnel obtain the paper invoice. The original bill is separated from the accounting voucher through image management. The paper invoice is scanned by the image management system. The high-speed scanner scans the original bill to generate image information, and uses the OCR sampling technology to identify the image information of the image management system. The paper invoice is summarized, archived and stored by the express mailing sharing center. In the network reimbursement mode based on financial sharing, the financial reimbursement process no longer takes the paper invoice as the standard. The scanned image data would be the auditing standard. The financial staff of the sharing center fills in the information

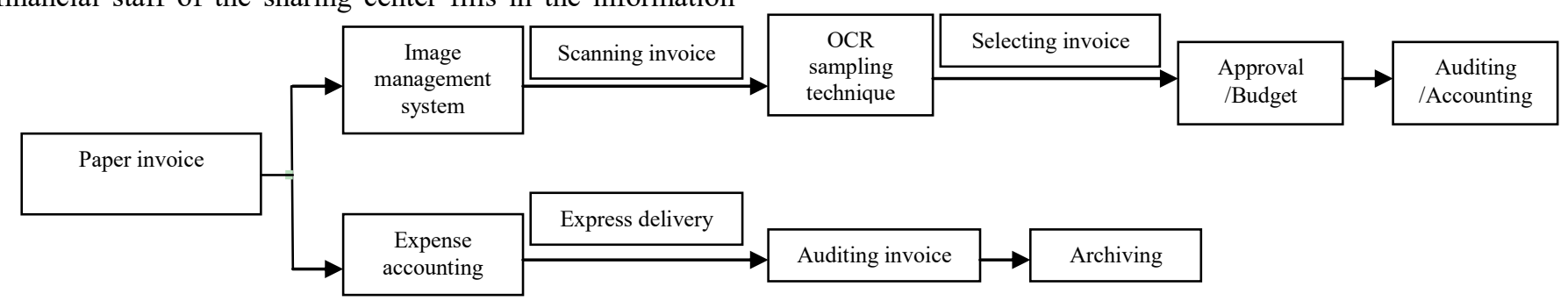

according to the image data, automatically generating the accounting voucher. The traditional online reimbursement requires that paper bills and approval processes should be carried out simultaneously. The financial sharing reimbursement process parallels the paper invoices and approval processes, effectively solving the problem of untimely approval of mobile office across space. [3]

The financial sharing reimbursement process also needs to balance the matching of physical bills and accounting vouchers. The new generation of financial sharing explorers represented by ZTE has creatively solved this problem by using barcode technology. [4] The employee submits the reimbursement document to the biller. The biller receives the bill through the barcode scanner. After the bill is sent, it will be scanned again. After receiving the bill, the sharing center will also scan the barcode, and the archived employee will also scan the bill. According to the arrival status of the barcode, the bill reviewer archives the paper invoice. The reimbursement process ends.

Fig. 1. Financial sharing reimbursement process.

\section{B. Problems in the Financial Sharing Reimbursement Model}

While the financial sharing center is accounted for by electronic voucher, it also needs to balance the circulation of physical bills. Although barcode technology can solve this problem, it also costs a lot of manpower and material costs. Large companies can achieve the financial sharing reimbursement model through image management and OCR sampling technology, while small and medium-sized enterprises will give up the financial sharing reimbursement model due to the cost.

After centralizing the scanning of bills and auditing of bills, the work will be boring. The enterprises will face the problem of staff loss. If the bills are backlogged, the enterprise can't operate smoothly. The review process with the KPI assessment mechanism as the core streamlined the accounting process. While improving the reimbursement rate of the company, it reduces employee satisfaction.

\section{The ELECTRONIC INVOICE REIMBURSEMENT MODEL}

\section{A. Electronic Invoice Reimbursement Process}

The electronic invoice can effectively solve the problem of the new reimbursement model of the financial sharing center. After the electronic invoice is electronically transferred, it does not need to take into account the physical bill at the same time. The financial sharing reimbursement process parallels the paper invoice and approval process, while the electronic invoice reimbursement process only requires the submission of image data. In the future, financial reimbursement will focus on employees, increase the efficiency of bill reimbursement, improve the reimbursement experience of employees, and save time costs of the staff. [5]

As shown in "Fig. 2", in the electronic invoice reimbursement mode, employee reimbursement only needs to upload the billing information to the invoicing party. The invoicing party opens a digitally signed electronic invoice on the electronic invoicing platform, and automatically pushes it to the salesperson's WeChat or email address. The electronic invoice obtained by the employee is imported into the OA system or ERP system. The reimbursement application is submitted. After the approval process, the reimbursement can be obtained. The electronic invoice reimbursement model is not only suitable for large enterprises that build financial sharing centers, but also for small and mediumsized enterprises. The electronic invoice reimbursement model truly breaks the problem of unreasonable reimbursement brought by the cross-space mobile office of the enterprise, and saves the express and travel costs brought by the physical invoice circulation. In the electronic invoice reimbursement mode, the accounting of the financial personnel has also become simple and quick. When the approval process is audited, the financial personnel can audit the finance. Even some enterprises that adopt the cloud service can directly generate the payment and receipt voucher. After the original information is verified correctly, 
the accounting voucher is generated, greatly improving the efficiency. Cashiers can also make quick payments, and employees can get real-time reimbursement. The reimbursement does not affect employee satisfaction and business progress.

Electronic invoices break the problem of mobile office work across space. Enterprises can focus on reimbursement business and conduct centralized management and control of reimbursement of various companies. This not only saves costs and improves efficiency, but also can retrieve data in real time, establish a budget mechanism, and carry out the fund management and control of enterprise costs, achieving pre-existing control, in-process control and post-event control in parallel. It is conducive to the prevention of financial risks.

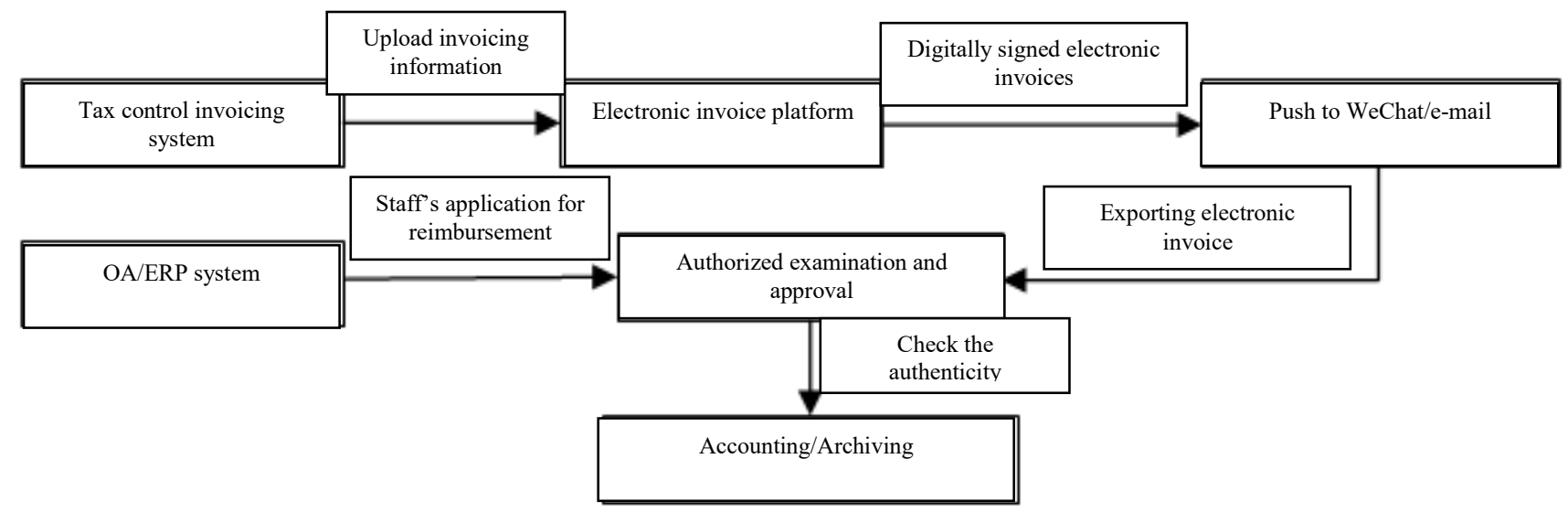

Fig. 2. Electronic invoice reimbursement process.

\section{B. The Difficulty in Implementing the Electronic Invoice Reimbursement Model}

1) Checking the authenticity of electronic invoices: At present, the electronic invoices received by the company's accounting personnel are usually used as the original bills by means of printing. However, the problems of tampering pictures, repeated reimbursement and false invoices brought by electronic invoices are difficult to verify. The original paper version of the invoice can be used to judge the authenticity of the invoice by empirically observing the quality of the paper and the anti-counterfeiting mark. Only when encountering the suspected fake bill, the inquiries are made on the website of the Inland Revenue Department. When using the electronic invoice, the website must be inquired one by one. People should make the self-checking of repeated print reimbursement. These undoubtedly increase the workload and risk of finance. Some companies resist the reimbursement of electronic invoices, resulting in resistance to the implementation of electronic invoices.

2) The input tax deduction of value-added tax special invoice: At present, China's "Regulations of the State Administration of Taxation on the Implementation of the Value-added Tax Electronic Invoices Issued by the Valueadded Tax Electronic Invoice System" (State Administration of Taxation Announcement No. 84 of 2015) stipulates that ordinary Value-added Tax invoices can be invoiced electronically. The enterprises can print the original bill as the reimbursement. However, the current value-added tax invoices have not achieved the electronization. The valueadded tax special invoices involve input tax deductions. The state has strict control over input taxes, which also hinders the full implementation of electronic invoices.

3) The invalidation process of electronic invoice: After the original paper invoice is issued incorrectly, the invoicing party applies for invalidation in the value-added tax invoicing system. At the same time, the invoicing party asks to return the wrong invoice before issuing a new invoice. Since the electronic invoice cannot be recovered, the printing can be repeated. Therefore, once the electronic invoice is issued, it cannot be invalidated. If the invoice is wrong, only red processing can be done. This difference does not increase the tax and cost of the invoicing party. However, it increases the risk of repeated reimbursement of the invoicing company. This risk can be avoided only by accounting personnel as accounting assistant.

\section{INTERNATIONAL EXPERIENCE IN APPLYING ELECTRONIC INVOICE REIMBURSEMENT MODEL}

The advantages of electronic invoices are obvious. However, there are also many risks. For example, it is difficult to verify the authenticity of invoices. At present, only ordinary invoices can be issued. The value-added tax input tax deduction cannot be issued. The re-repetitive nature of electronic invoices leads to repeated reimbursement of cancelled bills, etc. Therefore, we can learn from the successful experience of foreign countries. Brazil adopts a step-by-step method to implement electronic invoices, and combines goods and invoice circulation. The completion of invoice certification represents the completion of the sales process, achieving the purpose of "controlling taxation by bills" [6]. Taiwan's electronic invoices are divided into stubs and receipts, and the deposit certificate. The stub is saved by the seller; the receipt is saved by the purchaser; and the 
deposit certificate needs to be certified on the electronic invoice platform. The triple system of the electronic invoice is similar to the triple system of the value-added tax special invoice in China. The difference is electronic formal archiving [7]. The US national payment trading platform Paypal develops an electronic invoicing system. In 2013, it began to promote electronic invoices; the retailers installed tax-controlled cash registers; and invoice information was uploaded to the data center in real time [8]. Denmark began to use mandatory measures to implement the electronic invoice in 2004 (Rejection of paper invoices). The promotion of electronic invoices has achieved remarkable results [9]. The EU has started from large enterprises, and gradually infiltrated into small enterprises, which is achieved through the unification of the EU electronic invoicing system.

From the above experience of international electronic invoices, the implementation of electronic invoices requires the state to strengthen the promotion on the basis of strengthening the electronic invoicing platform. [10] At the same time, in order to solve the problem that the value-added tax special invoice cannot be implemented in electronic form, it is recommended that the country learn from foreign experience, as shown in "The improvement of electronic invoice reimbursement process" ("Fig. 3"). The value-added tax special electronic invoice is also divided into accounting, invoices, and deductions. The value-added tax ordinary invoices are also divided into accounting and invoices. After the seller opens the electronic invoice, the accounting is saved by the seller. The invoice is pushed to the customer's e-mail or WeChat. The salesman submits the invoice together with the reimbursement application to the finance, whether it is a special value-added tax invoice or an ordinary invoice, the finance must make the network certification. The network certification can prevent invalid invoices from reissuing, tampering data and fake invoices. The invalid invoices cannot be certified. Once the bill passed the certification cannot be revoked. It can only be revoked by notifying the bill collector to cancel the certification. After the certification is passed, the financial personnel will select the deductible input tax amount through the value-added tax input tax management website, and confirm the check to make the deduction.

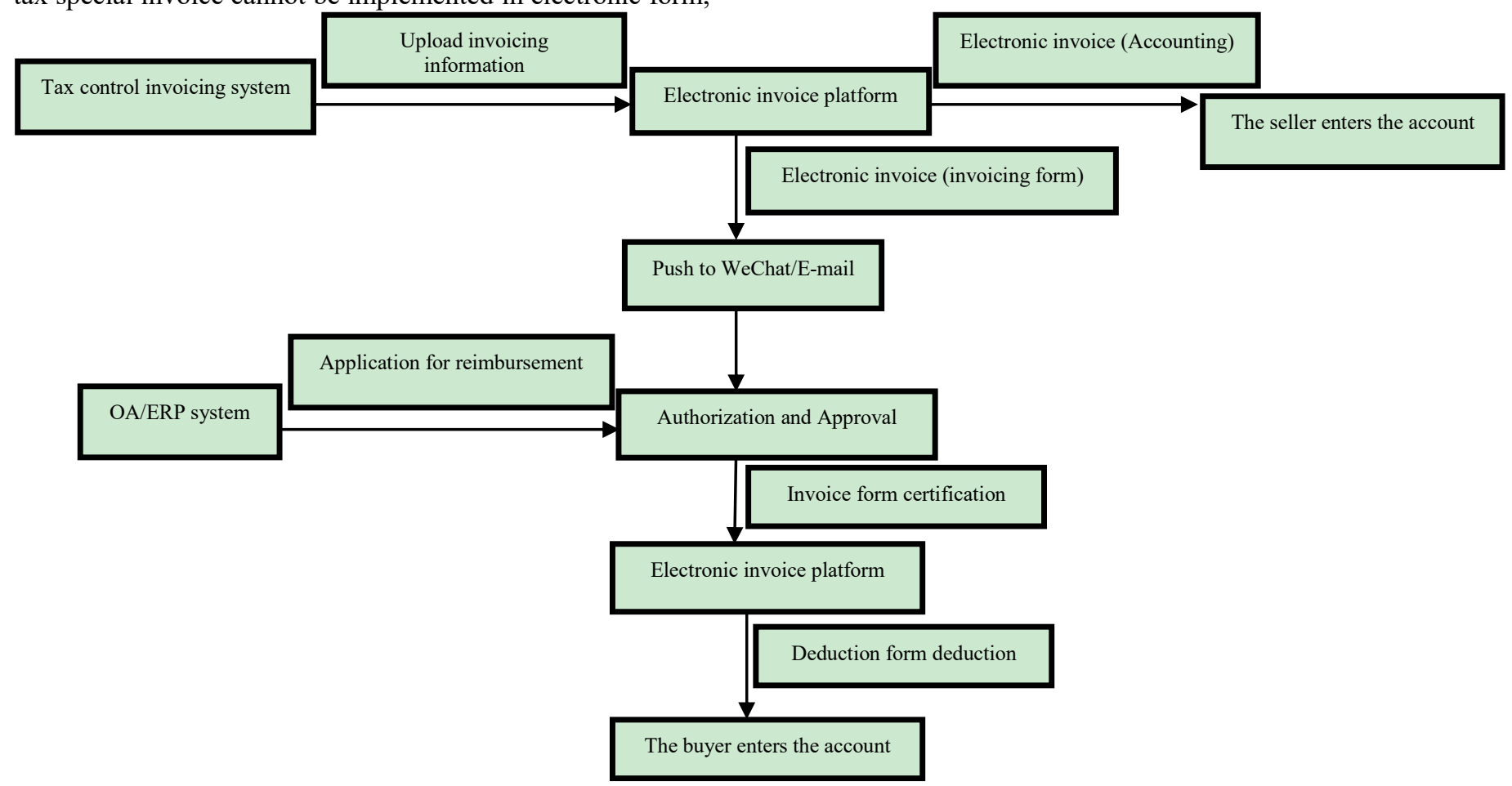

Fig. 3. The improvement of electronic invoice reimbursement process.

\section{CONCLUSION}

The implementation of electronic invoices helps national tax collection and management, reduces the printing, distribution and supervision costs of national paper invoices, helps enterprises improve reimbursement efficiency, truly realizing the reimbursement problem brought by cross-space mobile office. At the same time, the implementation of electronic invoices can promote the enterprise electronic file process, saving paper. It is good for the environment protection. [11] Most of the financial activities of enterprises are based on invoices. The reimbursement is an important part of corporate financial work. The financial reimbursement of Chinese enterprises goes through the traditional manual reimbursement process, the traditional online reimbursement process, the financial sharing invoice reimbursement process and the electronic invoice reimbursement process. Therefore, it is particularly important to reform the financial reimbursement process of enterprises through electronic invoices. At present, the difficulty in implementing electronic invoices lies in the fact that the traditional concept of enterprises has not changed. This must be guided and regulated through the issuance of relevant regulations at the national level. On the other hand, 
the electronic invoicing platform is not perfect. It is very difficult for enterprises to verify the authenticity of invoices. Special invoices cannot be issued with electronic invoices. There are loopholes in the process of invalidating electronic invoices. We need to pay attention to the problems that may arise in the application of electronic invoices. The future financial reimbursement after the application of electronic invoices will become more and more simple and quick. Therefore, combining with foreign experience, this paper puts forward the idea of improving the electronic invoice reimbursement process, hoping to give some advice and help for national taxation departments and enterprises.

\section{REFERENCES}

[1] Chai Yueting, Yu Xiao, Huang Yadong. Design and Implementation of Electronic Invoice Management and Public Service System[J]. Journal of Tsinghua University, 2018. DOI:10.16511/j. Cnki. Qhdxxb. 2018.26.020

[2] Angelica Cuylen, Lubov Kosch, Michael H. Breitner. Development of a maturity model for electronic invoice processes [J]. Electron Markets, 2016, 26: 115-127

[3] Zhang Zhenhao, Sun Yuefan. Financial shared service model design based on the cloud--taking the expense reimbursement process as an example [J]. Finance and Accounting, 2013 (07): 48-49.

[4] Chen Hu, Chen Dongsheng. Financial Shared Services Case Set [M]. Beijing: China Financial and Economic Publishing House, 2014: 1-20

[5] Chen Li, Liu Xianyun. The impact of electronic invoices on corporate finance under Internet + " environment $[\mathrm{J}]$. Friends of Accounting, 2016 (13): 92-93.

[6] Zhang Jinshan. Practice of electronic invoice in Brazil and countermeasures of deepening tax collection and management system reform in China [J]. Tax Research, 2017(05): 82-86.

[7] Jiunn-Woei Lian. Critical factors for cloud based e-invoice service adoption in Taiwan: An empirical study[J]. International Journal of Information Management, 2015, 35(1)

[8] Weng Chuyan. Adapting to local conditions and its own characteristics--Experience and inspiration of invoice management in foreign countries and Taiwan, China [J]. China Taxation, 2013 (06): 30-32

[9] Su Yufeng. The promotion and application of China's electronic invoices: based on international experience $[\mathrm{J}]$. Modernization of shopping malls, 2016(1): 216-217.

[10] Sun Yanli, Liu Juan, Dong Wentian, Lv Bin. Research on the Countermeasures of Electronic Invoice Promotion under the Background of "Internet +"--Taking Jingdong Mall Electronic Invoice as an Example [J]. Journal of Shenyang Jianzhu University (Social Science Edition), 2016, 18(06): 609-613.

[11] SALMONY M, HARALD B. E-invoicing in Eroupe :Now and the future [J]. Journal of Payments Strategy\&Systems, 2010, 4(4): 371380 